\title{
Should the elephant freeze for all?
}

\author{
Himanshu J. Patel, MD
}

From the University of Michigan Frankel Cardiovascular Center, Ann Arbor, Mich.

Disclosures: Author has nothing to disclose with regard to commercial support.

Received for publication April 1, 2016; accepted for publication April 1, 2016; available ahead of print May 4, 2016.

Address for reprints: Himanshu J. Patel, MD, Department of Cardiac Surgery, CVC Room 5144, 1500 E Medical

Center Dr, SPC 5864, Ann Arbor, MI 48109-5864 (E-mail: hjpatel@med.umich.edu).

J Thorac Cardiovasc Surg 2016;152:160-1

$0022-5223 / \$ 36.00$

Copyright $\subset 2016$ by The American Association for Thoracic Surgery

http://dx.doi.org/10.1016/j.jtcvs.2016.04.022

Several decades ago, Hans Borst and colleagues developed the elephant trunk procedure to aid in open treatment of extensive thoracic and thoracoabdominal disease requiring surgery. ${ }^{1}$ The advent of thoracic endovascular aortic repair signaled a shift in the approach to aortic repair, and it was soon thereafter that a hybrid approach to complex extensive thoracic pathology was developed. In this approach, ascending, arch, and descending aortic disease could be treated in a single stage with the combination of open surgery for the ascending and arch aorta along with the use of a thoracic stent graft in the descending thoracic aorta (frozen elephant trunk [FET]). ${ }^{2}$ This approach was applied in the treatment of extensive aneurysms as well as acute and chronic dissection.

In this issue of The Journal, Shrestha and colleagues ${ }^{3}$ report on 100 consecutive patients treated for aortic arch pathology with total aortic arch replacement with the Thoraflex Hybrid graft (Vascutek Ltd, a Terumo Company, Inchinnan, UK). This novel graft combines a woven polyester graft with a self expanding endoprosthesis on its distal end. This single-center study from an experienced aortic surgery group describes excellent outcomes in the treatment of acute and chronic dissections as well as degenerative aneurysms. Their reported mortality of $7 \%$ is commendable, particularly considering the fact that such high-risk pathology was treated and that the setting was reoperative in $28 \%$. Their follow-up is excellent and includes imaging data.

Evaluation of this novel graft's role should be assessed (as Shrestha and colleagues ${ }^{3}$ did) according to the type of pathology treated. In acute dissection, Shrestha and colleagues $^{3}$ suggest that FET aids in resolution of any potential malperfusion syndrome and prevents future aortic events. Although this was not assessed against a control group, the key questions include the following. First, should FET be performed in all patients undergoing an acute type A dissection repair? After all, is this not a lifesaving procedure with high reported mortalities without addition of a total arch replacement? Second, the technical questions of how long and how large a stent graft component to use are important in a pathology type that features no good distal landing zone. Shrestha and colleagues ${ }^{3}$ suggest that a 100-mm FET

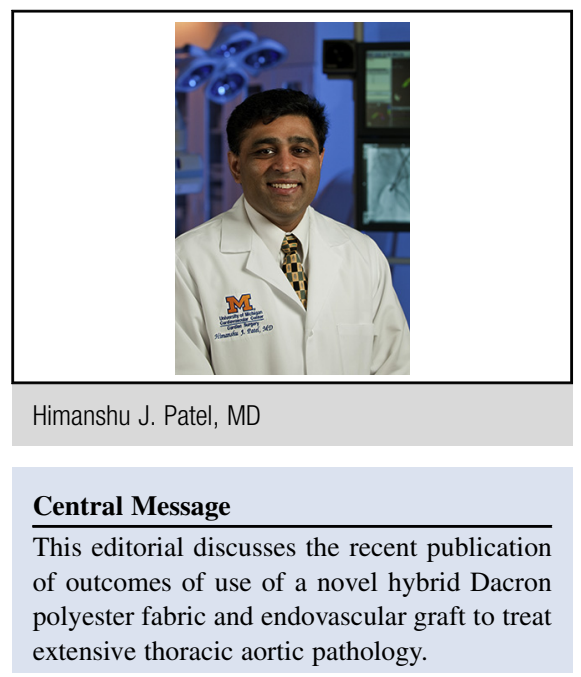

See Article page 148

See Editorial page 7

is adequate. For chronic aortic dissection, they suggest a $100 \%$ false-lumen thrombosis rate in the stented segment, but less gratifying results in distal sites. On the basis of previous reports, this does not come as a surprise. Finally, in the aneurysm cohort, the endoleak rate was initially quite high, which is not surprising given the recognized preoperative need for an additional procedure to achieve aneurysmal exclusion. Again, not surprisingly, the reintervention rate of $22 \%$ is not unexpected for these latter two pathologies.

Shrestha and colleagues ${ }^{3}$ should be congratulated on reporting these results; however, specific outcomes deserve special mention. A "new" complication for a proximal aortic operation was described. The incidence of spinal cord ischemia of $7 \%$ was not low. Reduction in this rate was proposed through the use of a shorter stent graft and selective spinal canal drainage. Second, the stroke rate of $9 \%$ also appeared quite high for this group, and its etiology was unclear. Third, a large number of reinterventions were performed with an endovascular approach.

All these findings lead to the suggestion that this novel graft configuration is an important addition to the armamentarium of an aortic specialist, but one that must be applied selectively. Not every acute type A dissection warrants FET, for there is likely a trade-off between increased neurological events and decrease in risk for future distal reintervention. FET in aneurysmal disease is an excellent choice as a single-stage procedure for a limited extent aneurysm. Finally, FET is best viewed as an improved 
initial stage procedure in patients who have chronic type A dissection or long segment thoracic aneurysmal disease, but planned reintervention is likely inevitable.

\section{References}

1. Borst HG. The birth of the elephant trunk procedure. J Thorac Cardiovasc Surg. 2013;145:44.
2. Karck M, Chavan A, Khaladj H, Hagl C, Haverich A. The frozen elephan trunk technique for treatment of extensive thoracic aneurysms: operative results and follow-up. Eur J Cardiothorac Surg. 2005;28:286-90; discussion 290

3. Shrestha M, Kaufeld T, Beckmann E, Fleissner F, Umminger J, Abd Alhadi F, et al Total aortic arch replacement with a hybrid frozen elephant trunk prosthesis: single-center results of the first 100 patients. J Thorac Cardiovasc Surg. 2016; 152:148-59. 